\title{
sciendo
}

\section{Frege's Puzzle and Cognitive Relationism: An Essay on Mental Files and Coordination}

Paolo Bonardi

University of Tokyo and eidos, the Centre for Metaphysics (Geneva)

BIBLID [0873-626X (2020) 56; pp.1-40]

\begin{abstract}
This paper will critically examine two solutions to Frege's puzzle: the Millian-Russellian solution proposed by Salmon and Braun, which invokes non-semantic modes of presentation (guises, ways of believing or the like); and Fine's relationalist solution, which appeals to semantic coordination. Special attention will be devoted to discussing the conception of modes of presentation as mental files and to elucidating the nature of coordination. A third solution to Frege's puzzle will be explored which, like Salmon's and Braun's, adopts the Millian-Russellian semantics but, like Fine's, involves coordination instead of modes of presentation; however, coordination will not be conceived as a semantic relation but as a cognitive and subjective relation, which provides no contribution to semantic content. This novel Millian-Russellian account involving cognitive coordination will be labelled cognitive relationism.
\end{abstract}

\section{Keywords}

Frege's puzzle, Millian Russellianism, mental files, semantic relationism, cognitive coordination.

This paper will critically examine two solutions to Frege's puzzle: the Millian-Russellian solution proposed by Nathan Salmon (1986, 1989 ) and David Braun (1998, 2002), which invokes non-semantic modes of presentation (guises, ways of believing or the like); and Kit Fine's (2007) relationalist solution, which appeals to semantic coordination. Special attention will be devoted to discussing the conception of modes of presentation as mental files (Recanati 2012, 2016) and to elucidating the nature of coordination. A third solution to Frege's puzzle will be explored which, like Salmon's and Braun's, adopts the Millian-Russellian semantics but, like Fine's, involves coordination instead of modes of presentation; however, coordination will not 
be conceived as a semantic relation but as a cognitive and subjective relation, which provides no contribution to semantic content. This novel Millian-Russellian account involving cognitive coordination will be labelled cognitive relationism.

\section{Frege's puzzle}

Let us introduce some notions and terminology.

Referential Difference: Two terms referentially differ if their referents differ.

Semantic Difference: Two expressions semantically differ if their semantic contents differ.

Semantic Content: The semantic content of a declarative sentence, $S$, in a context of use, $c$, or of a corresponding statement (i.e. an utterance or inscription of $S$ in $c$ ) is the proposition expressed by $S$ in $c$. The semantic content in $c$ of an expression $E$ comprised in $S$ is the contribution of $E$ (if any) to the semantic content of $S$ in $c$.

Cognitive Difference: Two statements cognitively differ if a (i.e. at least one) rational subject who understands them (i.e. who grasps their semantic content) can believe that one statement is true and the other is false at the same time. ${ }^{1}$

Consider the following identity statements about the planet Venus.

(1) Hesperus is Hesperus.

(2) Hesperus is Phosphorus.

Frege's puzzle can be presented as a list of five jointly inconsistent steps, (a)-(e).

\footnotetext{
${ }^{1}$ This characterization of cognitive difference, from Braun (2002: 66), is, in my opinion, preferable to alternative characterizations which invoke the notions of cognitive content, apriority or analyticity: according to some philosopher, specifically Salmon, statements like (1) and (2) have the same cognitive content (1986: ch. 1 and 2), and both are a priori true and analytic (1993a); if so, appealing to those notions leaves unexplained the intuition that (1) and (2) cognitively differ.
} 
(a) (1) and (2) cognitively differ.

$\therefore$ (b) (1) and (2) semantically differ. [From (a)]

$\therefore$ (c) "Hesperus" and "Phosphorus" semantically differ. [From (b)]

$\therefore$ (d) "Hesperus" and "Phosphorus" referentially differ. [From (c)]

(e) "Hesperus" and "Phosphorus" do not referentially differ. ${ }^{2}$

Frege's (1892) solution to his own puzzle, viz. the "Hesperus"/ "Phosphorus" case, consists in disallowing the move from step (c) to step (d): according to him, the semantic contents of "Hesperus" and "Phosphorus" are two different senses, i.e. two semantic modes of presentation of the unique denotation (or referent) of those names, Venus. After examining in $\$ 2$ Salmon's and Braun's Millian-Russellian solution to Frege's puzzle involving non-semantic modes of presentation, we will see in $\S 3$ and $\S 4$ that the notion of (semantic as well as nonsemantic) mode of presentation is subject to serious objections.

\section{Millian Russellianism, and Salmon's and Braun's solution to Frege's puzzle}

Millian Russellianism is a theory of meaning propounded by David Kaplan (1989), Nathan Salmon (1986, 1989), Scott Soames (1987), David Braun $(1998,2002)$ and other contemporary philosophers.

Millian Russellianism: According to this theory,

- the semantic content of a proper name and a singular demonstrative in a context of use is solely its referent (in that context);

- the semantic content of a predicate is an attribute (i.e. a property or a relation);

- the semantic content of a functor is a function;

${ }^{2}$ This formulation of Frege's puzzle, which does not aim at making any particular claim to historical accuracy, takes its cue from Fine 2007: 34. 
- the semantic content of any (declarative) sentence (in a context of use) or statement is a Russellian proposition, i.e. a structured proposition whose basic constituents are individuals, attributes and functions. A Russellian proposition is singular if it contains at least one individual as a constituent; otherwise it is general.

Millian Russellianism encompasses Millianism.

Millianism: The doctrine that the semantic content of a proper name is solely its referent.

Proponents of Millian Russellianism solve Frege's puzzle by disallowing the move from step (a) to step (b). According to them, statements (1) and (2) do not semantically differ: both express the singular proposition (represented by the sequence) (1p) (below). On the other hand, these statements cognitively differ: coherently with Cognitive Difference (\$1), a rational subject, say Hammurabi, who understands (1) and (2) can believe that (1) is true and (2) is false at the same time. Thus, taking for granted Millian Russellianism, Hammurabi simultaneously believes and disbelieves (i.e. believes false) the same Russellian proposition, (1p). But how can he do so rationally?

$$
\text { (1p) }<\text { Venus, =, Venus }>
$$

Salmon and Braun answer this question by appealing to the notion of non-semantic mode of presentation, viz. a mode of presentation that does not contribute to semantic content. More precisely, Salmon appeals to guises, which are pragmatic and public modes of presentation (Salmon 1986, 1989), whereas Braun appeals to ways of believing, which are psychological and private modes of presentation, viz. Mentalese sentences (Braun 1998). ${ }^{3}$ According to Salmon and Braun, Hammurabi believes the singular proposition (1p) under the mode of presentation corresponding to (1) and disbelieves it under a different mode of presentation, corresponding to (2), without realizing they are modes of presentation of the same thing (viz. of the same Russellian proposition). Importantly, the relationship between non-semantic as well as semantic modes of presentation and rationality is established by the following constraint called by Stephen Schiffer (1990) Frege's Constraint.

${ }^{3}$ A Mentalese sentence is a sentence belonging to Mentalese, i.e. Fodor's hypothetical language of thought. 
Frege's Constraint: A rational subject cannot simultaneously believe and disbelieve one thing, viz. $a$ to $F$, (i) under the same mode of presentation, or (ii) under different modes of presentation which the subject realizes are modes of presentation of the same thing. ${ }^{4}$

But what exactly are modes of presentation? We can first of all observe that a mode of presentation, $m$, of an object, $o$, is either (j) descriptive or (jj) non-descriptive.

Descriptive mode of presentation: Something like a property, not including $o$ as a constituent, which is (correctly or incorrectly) taken by one or multiple subjects to be uniquely exemplified by $o .^{5}$

In $\S 3$ and $\S 4$ I will respectively examine options (j) and (jj), showing that both meet severe obstacles. Since (j) and (jj) are collectively exhaustive and mutually exclusive, I will deduce that modes of presentation must be given up as a tool indispensable to solve Frege's puzzle.

\section{Descriptive modes of presentation and the "Bruce" puzzling case}

The doctrine that modes of presentation are descriptive is defended by Soames (2002), according to whom the role of modes of presentation is played by general propositions. Arguably, some twodimensionalists also endorse this doctrine with respect to primary intensions.

${ }^{4}$ Salmon (1989: 257-8, 2006: 370) endorses this constraint. Officially, Braun (2006) does the same. But by reading Braun and Saul 2002, one is led to the conclusion that Braun only endorses part (i) of Frege's Constraint, while he rejects part (ii): for him and Jennifer Saul, a rational subject $s$ is allowed to deploy different modes of presentation, viz. mental files, even when $s$ realizes are files about the same object. Concerning the rejection of part (ii) of Frege's Constraint within a theory of mental files, see $\S 4.1$ of the present manuscript.

${ }^{5}$ There is also a stronger sense in which a mode of presentation can be said to be descriptive: if it is like a property, not including $o$ as a constituent, that is indeed uniquely exemplified by $o$; see Recanati 2012: 12 on this. As the reader will be able to verify by herself, the difficulty I will raise in $\S 3$ about the conception of descriptive modes of presentation indicated above also applies to the stronger conception mentioned in this footnote. Moreover, such a stronger conception is challenged by Kripke's (1980) so-called semantic argument against descriptivism. 
If modes of presentation are descriptive, then Braun's and Salmon's proposal presented in $\S 2$ is unable to solve a particular version of Frege's puzzle due to Fine (2007), the "Bruce" case.

[L]et us imagine a universe that is completely symmetric around [Susan]'s center of vision. Whatever she sees to her left is and looks qualitatively identical to something she sees on her right (not that she conceptualizes the two sides as "left" and "right" since that would introduce an asymmetry). She is now introduced to two identical twins, one to her left and the other to her right, and she simultaneously names each of them "Bruce"; using a left token of "Bruce" for the left twin and a right token of "Bruce" for the right twin. The two tokens of "Bruce" are then always used in tandem so as not to disturb the symmetry. Thus if she uses a left token of "Bruce" to say "Bruce is wearing pink pajamas", she simultaneously uses a right token of "Bruce" to utter the same thing. She can even assert the non-identity of the two Bruces by simultaneously uttering the one token of "Bruce" from the left side of her mouth, the other token from the right, and a word for non-identity from the middle of her mouth.

[...] We can even suppose that she is originally introduced to one person[, Bruce,] but, seeing him "double", takes him to be two people. (Fine 2007: 36; underlining mine) ${ }^{6}$

[Susan then] starts to have simultaneous thoughts with identical [Russellian] content about what each of the supposed two people is like (he is wearing pink pajamas, he is smiling in a funny way, etc.). It is clear that she is having two sets of singular thoughts about Bruce. [... A mode-ofpresentation theorist would like to say] that Bruce is given through one mode of presentation in the one set of thoughts and through another mode of presentation in the other set of thoughts. But there is nothing sensible we can say as to what these modes of presentation might be. There can be no purely descriptive difference between them, since there is no purely descriptive difference in the way that [Susan] conceives of the two Bruces [...]. (Fine 2007: 71; underlining mine)

${ }^{6}$ For the purposes of this paper, Fine's "Bruce" case should be modified so that Susan does not introduce two names "Bruce" for the two alleged twins (otherwise these names might play the role of different modes of presentation of Bruce) but rather she learns from someone a unique name "Bruce" that she mistakes for two indistinguishable names. 
The "Bruce" case can be presented as a version of Frege's puzzle. Susan is a rational subject who mistakes one individual, Bruce, for two twins appearing to her as indistinguishable (indiscernible). She sincerely dissents to statement $\left(3^{* *}\right)$ produced by someone with the intention to refer to the two alleged Bruces (but de facto referring to the uniquely existent Bruce), while she sincerely assents to statement $\left.3^{*}\right)$ produced by someone with the intention to refer to the same Bruce (one of the two alleged Bruces). Now, if in steps (a)-(e) (\$1) we replace (1), (2) with $\left(3^{*}\right),\left(3^{* *}\right)$ and "Hesperus", "Phosphorus" with the token names "Bruce" contained in $\left(3^{* *}\right)$, we obtain the desired new version of Frege's puzzle.

$\left(3^{*}\right)$ Bruce is Bruce. [Produced with the intention to refer to the same Bruce]

$\left(3^{* *}\right)$ Bruce is Bruce. [Produced with the intention to refer to the two alleged Bruces but de facto referring to the same]

Braun's and Salmon's proposal fails to solve the "Bruce" case if modes of presentation are descriptive, because it fails to account for the cognitive difference between $\left(3^{*}\right)$ and $\left(3^{* *}\right)$ : no two descriptive modes of presentation of Bruce are available to Susan, as a consequence of the fact that the two alleged Bruces appear to her as indiscernible, i.e. as having the same properties. ${ }^{7}$ So, in order to solve the "Bruce" case in terms of modes of presentation, Salmon and Braun would need to postulate that modes of presentation are non-descriptive.

4 Non-descriptive modes of presentation, viz. mental files, and the problems of their definition and identity

One of the most important conceptions of non-descriptive modes of presentation, towards which both Salmon (1986: 120) and Braun

${ }^{7}$ It could be replied that two descriptive modes of presentation of Bruce are available to someone who (like Susan) mistakes Bruce for two twins but (unlike her) has the concepts of left and right; this subject could be involved in a successful account of the cognitive difference between $\left(3^{*}\right)$ and $\left(3^{* *}\right)$. I wish to note, nevertheless, that this reply is ineffective against a modified version of the "Bruce" case, where the two alleged Bruces are two electrons having the same physical properties and the same probability of being located in a given spatial region. 
(in Braun and Saul 2002: §4) appear sympathetic, is that of mental files (or clusters of information about objects stored in the subjects' minds). We will examine the most known theory of mental files: Recanati's.

What exactly is for Recanati a mental file? Answering this question is not easy, given the richness of files of different sort that Recanati's theory comprises: token vs. type/public files, regular vs. vicarious or indexed files, static vs. dynamic files, merged and partially-merged files, demonstrative files, memory files, composite files, higher-order files, recognitional files, encyclopaedic files, proto-files, etc. A characterization of a mental file that many scholars of Recanati will probably find appropriate is the following.

Mental file (first characterization): A mental file maintained by a subject, $s$, is a repository for Mentalese predicates which $s$ (correctly or incorrectly) takes to be true of one and the same object. ${ }^{8}$

In Recanati's theory, mental files are typically based on tokenreflexive relations to the objects the files are about; also, mental files are sometimes linked to other files. Roughly, token-reflexive relations are token acquaintance (epistemically rewarding) relations between the bearers of the files and the objects those files are about; ${ }^{9}$ and two files

${ }^{8}$ See Recanati 2012: 43n1 and 2016: 11.

9 The phrase “token acquaintance relation" can be found in Recanati 2012: 257 (underlining mine). Recanati has a quite liberal conception of acquaintance. On his view, acquaintance includes perception of physical objects, memory of perception, introspection, proprioception, kinaesthesis and even testimony (2013: 208). Relations that are obtained by composing acquaintance relations are also regarded as acquaintance relations. E.g. the relation holding between a user $s$ of a proper name $N$ introduced by ostension and its bearer $o$ is an acquaintance relation, being constituted of two simpler acquaintance relations: the branch of the causal-historical chain associated with $N$ and holding between $s$ and a baptizer, $s^{*}$, of $o$, which can be regarded as a relation of testimony; and the perceptual relation holding, during o's baptism, between $s^{*}$ and $o$ (2012: 34-5n5, 103). Acquaintance relations belong to the larger class of epistemically rewarding (ER) relations, which also includes re-acquaintance relations (2012: 86) and familiarity relations (2012: 71).

Strictly speaking, token-reflexive relations are not token ER (and thus acquaintance) relations. For, first, an ER relation holds between the bearer of the file and the object the file is about, whereas a token-reflexive relation holds be- 
respectively about objects $o$ and $o^{*}$ are said to be linked if their bearer (correctly or incorrectly) judges that $o$ is identical to $o^{*}$ (Recanati 2012: 84). Token acquaintance relations and linking are the two sorts of channels via which information reaches the files, there assuming the form of Mentalese predicates. It should be noted that files are not always based on acquaintance relations: e.g. files concerning future objects are acquaintanceless (2012: ch. 12 and 13).

By appealing to the notion of a mental file, Recanati is able, in principle, to solve the "Bruce" case (§3). Susan maintains two indiscernible files about Bruce, which store Mentalese predicates of the same type (2012: 41) and which are originally based on two indiscernible token visual relations from Susan to the uniquely existent Bruce. The hypothesis that Susan maintains two numerically distinct files about Bruce suffices to account for the cognitive difference between $\left(3^{*}\right)$ and $\left(3^{* *}\right)$, while the fact that they are indiscernible matches the symmetry of Susan's and Bruce's universe described by Fine (2007: 36).

As I will argue in $\S 4.2$ and $\S 4.3$, nevertheless, the notion of a mental file (characterized as above) is unsatisfactory in multiple counts. Moreover, a persuasive solution to the "Bruce" case in terms of files would require that accurate identity conditions for them were specified (§4.4). Before facing these critical issues, let us clarify, in $\S 4.1$, Recanati's (2012: 34) central thesis (T1).

(T1) (Non-descriptive) modes of presentation are mental files.

tween the file itself and the object (2012: 69-70). Second, ER relations and token-reflexive relations play different roles: the former is, together with linking, the channel via which the (mis)information stored in the file is gained (2012: 82), whereas the latter is what fixes the referent of the file (2012: 70-1n1). Incidentally, files refer because, according to Recanati (2012: 182), they are Mentalese singular terms; also, as a result of being non-descriptive modes of presentation, files have their referents fixed not by the information stored in the files (fn. 5 of the present manuscript) but by their token-reflexive relations. Despite all these differences, since "[the token-reflexive relations] are typically characterized in terms of the [ER] relations" (2012: 69) and since the ER relations are paradigmatically exemplified by the acquaintance relations, henceforth I will just talk of acquaintance relations, omitting to consider the differences between them and the token-reflexive relations. 


\subsection{Clarifications concerning thesis (T1)}

According to Recanati, a subject can maintain distinct files even by realizing, in contrast with part (ii) of Frege's Constraint, that they are about the same object: this is exactly what happens in the case of linked files (above). Therefore, thesis (T1) is admissible within Recanati's theory only if Frege's Constraint (end of §2) is given up as the correct constraint governing the relationship between modes of presentation (viz. mental files) and rationality, and is replaced with part (i) of Frege's Constraint only. ${ }^{10}$

But even after this clarification, thesis (T1) appears false or highly imprecise. For, as Recanati maintains, mental files are Mentalese singular terms (2012: 182), viz. Mentalese Millian terms (2016: vii) or Mentalese definite descriptions (2013: 212), or perhaps even Mentalese indefinite descriptions (2012: 236); however, they are not Mentalese predicates, for the following reason. Since the items of information stored in the files are conceived by Recanati as Mentalese predicates, if Mentalese predicates were in turn files, an endless regress would arise: in principle, files would contain files, which in turn would contain other files and so on ad infinitum. Reasonably, while mental files, viz. Mentalese singular terms, are modes of presentation of individuals, Mentalese predicates are modes of presentation of attributes. So, what Recanati means by (T1) is (T2) (below); and mental files are things that satisfy Frege's Constraint* (below).

(T2) (Non-descriptive) modes of presentation of individuals are mental files.

Frege's Constraint*: A rational subject cannot simultaneously believe and disbelieve $a$ to $F$, thinking of the object $a$ by deploying the same mental file and thinking of the property $F$ by deploying the same Mentalese predicate.

Furthermore, it should be pointed out that not only Mentalese expressions are modes of presentation: as maintained by Braun and Saul (2002), images and, more generally, items of acquaintance are also

${ }^{10}$ Recanati affirms that modes of presentation are subject to Frege's Constraint. But what he means by "Frege's Constraint" is clearly part (i) of this constraint: see his formulation of "Frege's Constraint" in 2012: 221 and 2016: ix. 
modes of presentation within a mental-file framework. An appropriate way to generalize thesis (T2) within such a framework would then be (T3) (below).

(T3) (Non-descriptive) modes of presentation are Mentalese expressions (e.g. mental files) or items of acquaintance.

It follows from (T3) that a theory of mental files is not sufficient for a comprehensive theory of non-descriptive modes of presentation: the former needs to be integrated with a theory of Mentalese predicates and, more generally, of Mentalese expressions that are not mental files, along with a theory of acquaintance.

Let us now focus on mental files (characterized as at the beginning of $\S 4)$.

\subsection{Doubts about mental files}

A first flaw of the characterization of mental files proposed at the beginning of $\S 4$ (first characterization) is that it does not apply to all files of Recanati's theory. In particular, it does not apply to type and public files, which are instantiated/shared by multiple subjects: ${ }^{11}$ the characterization in question explicitly talks of a file maintained by a subject $s$, hence a subjective, private or token file. It does not also apply to vicarious or indexed files, i.e. files that stand in the subject's mind for other subjects' files: e.g. my HESPERUS file indexed to Hammurabi does not contain the Mentalese predicates I (or Hammurabi) take(s) to be true of Venus, but it contains the Mentalese predicates that I (correctly or incorrectly) think Hammurabi takes to be true of Venus qua Hesperus.

Even if we put aside type, public and vicarious files, the characterization of mental files formulated at the beginning of $\S 4$ appears unacceptable: as it stands, it is paradoxical. For suppose that Tom's belief box (i.e. the box containing all Mentalese sentences Tom believes true) contains the Mentalese sentences CICERO IS NOT CAESAR (to the effect that Tom knows that Cicero and Caesar are

\footnotetext{
${ }^{11}$ Concerning type files, see Recanati 2012: 60. Concerning public files, see Recanati 2012: 201, 205 and see also 2016: interpersonal dynamic files (2016: 124) and distributed files (2016: §8.3) are public files.
} 
different people) and CICERO ADMIRES CAESAR. Since for Recanati Mentalese names are mental files (viz. encyclopaedic files), Tom maintains distinct files about Cicero and Caesar, respectively the CICERO file and the CAESAR file: the former stores the Mentalese predicate ADMIRES CAESAR and therefore Tom's CAESAR file; the latter stores the Mentalese predicate IS ADMIRED BY CICERO and therefore the CICERO file. In sum, both the CICERO file contains the CAESAR file; and the CAESAR file contains the CICERO file. It follows that the CICERO file is identical to the CAESAR file, which is absurd: since by supposition Tom knows that Cicero is not Caesar, his CICERO file and his CAESAR file must be distinct. ${ }^{12}$

\footnotetext{
12 This paradox can be seen as a development of an objection about files and relations raised by Kaplan (2011: 167n24). Recanati (2012: 50) has affirmed that "[i]nformation sharing between files can be represented in various ways: by duplicating the information ([ADMIRES CAESAR in the CICERO file, IS ADMIRED BY CICERO in the CAESAR file]), or by storing the information in a single file and introducing into the other file a pointer to the first file so as to make the shared information accessible from the second file”. As we have just seen, Recanati's first proposal (i.e. duplicating the shared information) generates the paradox. Regarding the second proposal (i.e. introducing into one file a pointer to another file), it is unclear what exactly a pointer is. In addition, the following question arises: is the Mentalese predicate ADMIRES CAESAR stored in the CICERO file and made accessible from the CAESAR file through a pointer or, vice versa, is the Mentalese predicate IS ADMIRED BY CICERO stored in the CAESAR file and made accessible from the CICERO file through a pointer? Which criterion could determine a choice between these two alternatives?
}

In response to the question of what pointers are, François Recanati in personal communication has suggested that instead of pointers to files, we could talk of labels of files (2012: 40n12). If so, e.g. in ADMIRES CAESAR (let us rewrite it as ADMIRES CAESAR in order to avoid confusion), CAESAR would not be the Mentalese name or file CAESAR but a label of it. On the other hand, such a label is clearly linguistic and mental. To which mental language does it belong? If it belongs to Mentalese, then it is presumably a Mentalese name of CAESAR (i.e. a Mentalese name of a Mentalese name) and hence it is a file (let us call it a label file). At this point, nevertheless, we would need an account of label files, which explains e.g. what sort of information label files store. (Note that if they in turn somehow stored label files, there would be the risk of an endless regress: label files might contain label files, which in turn might contain other label files and so on ad infinitum.) Whatever a label of a file is, it does not seem that ADMIRES CAESAR within Tom's CICERO file correctly represents what Tom thinks of Cicero: he thinks that Cicero admires Caesar, not that Cicero admires the CAESAR file. 


\subsection{Mental files revisited and further doubts}

I can see only one plausible way for Recanati to escape the paradox presented in $\$ 4.2$ : to conceive not only the Mentalese identity predicate IS (viz. identity judgment) as he (2012: ch. 4) already does but all Mentalese relational predicates as links between files (of course, links of a different nature than the identity link). ${ }^{13}$ By adopting this proposal, the two-place predicate ADMIRES would not be contained in any file, viz. not in the CICERO file and not in the CAESAR file; rather, it would be a link between these two files. In this way, the illustrated paradox would vanish. Taking into account such a proposal along with other considerations made in $\$ 4.2$, the previously proposed characterization of mental files could be modified as follows.

Mental file (second characterization): A token and non-vicarious mental file maintained by a subject $s$ is a repository for both Mentalese non-relational predicates and items of acquaintance which $s$ (correctly or incorrectly) takes to be true of / to be about one and the same object.

As I am now going to show, nevertheless, this revision also encounters difficulties (besides the obvious one of not providing an exhaustive characterization of files, due to its being inapplicable to type, public and vicarious files). We said in $\$ 4.1$ that if mental files (tokens), viz. Mentalese singular terms, are modes of presentation of individuals, then Mentalese predicates will reasonably be modes of presentation of attributes. On the other hand, suppose that Tom's belief box contains the Mentalese sentences CICERO WALKS and CAESAR WALKS, and consider the Mentalese predicate WALKS stored in Tom's CICERO file and the Mentalese predicate WALKS stored in his CAESAR file. Taking into account that according to Recanati (2012: 50) mental files do not usually overlap/intersect, the predicate WALKS stored in one file will be distinct from the predi-

\footnotetext{
${ }^{13}$ This manoeuver — which echoes an idea developed by Jim Pryor (2016) would also allow Recanati to straightforwardly reply to an objection raised by Michael Murez (2011) concerning the unjustified asymmetry in Recanati's theory between the Mentalese identity predicate (conceived as a link among files) and the other Mentalese relational predicates (conceived as items of information within the files).
} 
cate WALKS stored in the other file. ${ }^{14}$ Hence, Tom should have (at least) two distinct modes of presentation of the property of walking. But this conclusion is untenable: we can certainly assume that Tom makes no error on the identity of such a property and has only one mode of presentation of it. So, either, contrary to what we said in $\S 4.1,(j)$ Mentalese predicates are not modes of presentation; or, pace Recanati, (jj) the information stored in the files are not Mentalese predicates. Maintaining that (j) Mentalese predicates are not modes of presentation of attributes whereas mental files, viz. Mentalese singular terms, are modes of presentation of individuals would introduce a strange asymmetry in Recanati's theory. Moreover, if modes of presentation of attributes were not Mentalese predicates, what would they be within a mental-file framework? On the other hand, if (jj) the items of information gathered in the files are not Mentalese predicates, it is hard to say what they could be. ${ }^{15}$

Regardless, even the second characterization of mental files with the neutral phrase "non-relational items of information" in the place of "Mentalese non-relational predicates" is problematic: it fails to provide a necessary condition for being a mental file. In fact, as it was clarified in the first part of $\S 4$, on Recanati's view, information can enter a given file via channels of two kinds only: the acquaintance relation between the bearer of the file and the object the file is about; and the links between the file in question and other files maintained by the same subject. Now, consider my NEWMAN-1 file, i.e. the file I cognitively associate with the name "Newman-1", whose referent was famously fixed by Kaplan (1968: 201) using the description

${ }^{14}$ Although files do not usually overlap/intersect, there is room in Recanati's rich theory for sub-files, i.e. files contained in other files. Examples of sub-files are: proto-files (2012: 64-7, 99-101); indexed files (2012: 183); and static files, which can be regarded as sub-files of dynamic files (as regards static and dynamic files, see the last part of $\S 4.4$ of the present manuscript).

${ }^{15}$ Following a suggestion from Recanati mentioned in $\mathrm{fn} .12$, it could be maintained that those items are labels of Mentalese predicates. If so, Tom's CICERO file and the CAESAR file would contain two labels of the Mentalese predicate WALKS, say WALKS 1 and WALKS 2 . As we have seen in fn. 12, nevertheless, this sort of proposal encounters difficulties. In particular, it fails to correctly represent what Tom thinks of Cicero: Tom thinks that Cicero walks, not that Cicero (stands in some relationship with) the Mentalese predicate WALKS. 
"the first child to be born in the twenty-second century". Suppose that this file is linked to no other files of mine. My mind contains information concerning the currently nonexistent, viz. future, individual Newman-1: WILL BE A MAN; WILL LIVE DURING THE TWENTY-SECOND CENTURY; etc. Nevertheless, this information is not in my NEWMAN-1 file, because it can enter such a file in no way. In fact, no epistemic channel is available to carry information from Newman-1 to my NEWMAN-1 file: by assumption, this file is unlinked; and, as Recanati (2012: ch. 12) himself maintains, files concerning future individuals like Newman-1 are based on no acquaintance relations. It follows that my NEWMAN-1 file is empty, and therefore it is not the repository for my information concerning Newman-1, in contrast with all characterizations of mental files considered so far (according to which a file about an object is a repository for information concerning that object). ${ }^{16}$

Hence, all such characterizations do not provide a necessary condition for being a mental file. It is also doubtful that they provide a sufficient condition for it, given that the items of information (tokens) a subject takes to be true of / to be about the same object may be stored in distinct (linked) files. This is especially evident in a case like the following, involving the process of partial merging. Consider a rational subject, Emily, who realizes that Superman is Clark Kent after having wrongly thought they were two different individuals. According to Recanati (2012: 111-2), Emily may open a new inclusive file, the SUPERMAN / CLARK KENT file, whilst leaving open the initial SUPERMAN file and CLARK KENT file. Now, although Emily takes the items of information stored in the two initial files, e.g. CAN FLY (stored in the SUPERMAN file) and CANNOT FLY (stored in the CLARK KENT file), to be true of the same individual, she keeps

${ }^{16}$ Keith Hall (2013: 130) has worries similar to mine about files on future individuals. It is worth noting that cases analogous to the "Newman-1" case also arise with nonexistent individuals/objects that are merely possible or metaphysically impossible; examples of such individuals/objects can be found in Salmon 1998: 286-8.

I am not convinced that Recanati's proposal of appealing to expected acquaintance (2012: 164-7) or imagined acquaintance (2012: 168) resolves the "Newman-1" case and the like: it is hard to see how an expectation or imagination/ pretence of an epistemic channel would in turn be an epistemic channel. 
them separated; in fact, if both contradictory items were stored in one and the same file, Emily would be irrational, in contrast with our initial supposition. ${ }^{17}$

At this point, it seems that the only viable strategy for convincingly characterizing files and, more generally, non-descriptive modes of presentation consists in determining clear identity conditions for them. Knowing such conditions would also be important to uncontroversially solve the "Bruce" version of Frege's puzzle, where the presence of two numerically distinct modes of presentation of Bruce maintained by Susan instead of just one is open to debate, given her mistaking Bruce for two indiscernible individuals.

\subsection{The problem of the identity of non-descriptive modes of presentation, viz. mental files}

Although in his books 2012 and 2016 Recanati has not specified the identity conditions for mental files (viz. de facto identity conditions applicable to all files), some hypotheses regarding how files could be individuated might be put forward taking cue from his theory of files and from other theories of non-descriptive modes of presentation.

In particular, one could hypothesize that mental files are individuated using Frege's Constraint ${ }^{*}(\$ 4.1)$ along the lines sketched in the following paradigmatic example. Suppose that Peter rationally and simultaneously believes the singular propositions (4p) and ( $4 p)$ (below), where NEG is the function of negation. Based on Frege's Constraint, it could be argued that Peter deploys two mental files about Paderewski, one cognitively associated with Paderewski's occurrence in (4p) and the other cognitively associated with his occurrence in $(\sim 4 p)$.

\footnotetext{
${ }^{17}$ See Recanati 2012: 43n1. The "Superman"/“Clark Kent" case is also a counterexample to Recanati's (2012: 94) characterization of linked files as files whose information flows freely from one (linked) file to another: although the SUPERMAN file and the CLARK KENT file are linked, the item of information CAN FLY does not flow from the former file to the latter and, vice versa, the item of information CANNOT FLY does not flow from the latter file to the former; in addition, neither of these items of information flows to the inclusive SUPERMAN / CLARK KENT file, even though this file is linked with both the SUPERMAN file and the CLARK KENT file.
} 
(4p) $<$ Paderewski, having musical talent $>$

$(\sim 4 p)<<$ Paderewski, having musical talent $>$, NEG $>$

This proposal is actually defective in various respects, starting from the example above: the correct conclusion one should infer using Frege's Constraint ${ }^{*}$ from the supposition that Peter rationally and simultaneously believes ( $4 p)$ and $(\sim 4 p)$ is that either (i) Peter associates distinct files with the two occurrences of Paderewski in (4p) and ( 4p) or (ii) he associates distinct Mentalese predicates with the two occurrences of the property of having musical talent within these propositions. The conclusion that (i*) Peter maintains distinct files about Paderewski is more plausibly deducible, using again Frege's Constraint ${ }^{*}$, from the supposition that Peter rationally and simultaneously believes the propositions (5p) and ( $\sim 5 p)$, i.e. $\left(\sim 5 p^{*}\right)$ (below). Note, however, that even in this further case it is possible in principle that Peter associates $\left(\sim i^{*}\right)$ the same file with each occurrence of Paderewski in (5p) and $\left(\sim 5 \mathrm{p}^{*}\right)$, and $\left(\mathrm{ii}{ }^{*}\right)$ different Mentalese predicates with the two occurrences of the identity relation in these propositions. In sum, Frege's Constraint ${ }^{*}$ does not allow us to make a choice between the options $(\mathrm{i}) /\left(\mathrm{i}^{*}\right)$ and (ii)/(ii*).

$$
\begin{aligned}
& (5 \mathrm{p})<\text { Paderewski, }=\text {, Paderewski }> \\
& (\sim 5 p)<\text { Paderewski, } \neq \text {, Paderewski }> \\
& \left(\sim 5 p^{*}\right)<<\text { Paderewski, }=\text {, Paderewski }>, \text { NEG }>
\end{aligned}
$$

But let us concede, for the sake of argument, that option ( $\left.\mathrm{i}^{*}\right)$ is the case, viz. that Peter associates two files, $f_{1}$ and $f_{2}$, with the two occurrences of Paderewski in $(\sim 5 p) /\left(\sim 5 p^{*}\right)$ and the file $f_{3}$ with both occurrences of Paderewski in (5p). Is $f_{3}$ the same file as $f_{1}$ or the same file as $f_{2}$ or a third file distinct from both $f_{1}$ and $f_{2}$ ? Again, Frege's Constraint* does not help us to answer this question. We have then to conclude that such a constraint is not sufficient to solve the problem of the identity of mental files.

Alternatively, based on a proposal by Mark Sainsbury and Michael Tye (2012), it could be hypothesized that a mental file is individuated by its origin. But what exactly is the origin of a file? If "origin" stands for the event/occasion in which the file is opened, then Sainsbury's and 
Tye's proposal is arguably falsified by cases where distinct files originate in the same circumstance. This might happen e.g. in the "Bruce" case: given the perfect symmetry of the universe where Susan and Bruce are located, Susan's two files about Bruce could have originated in the same event mistaken by her for two indiscernible events. On the other hand, if - as Sainsbury, Tye and Ruth G. Millikan (2011: 102) actually suggest - “origin" stands for the first use/deployment of the file/concept, the hypothesis under discussion can be criticized on the ground that it is not exhaustive: intuitively, a file can be opened without being deployed in the moment of its opening or even later (in principle, a file can be opened by a subject and never deployed by her). To this, it might be replied that the openness of a file is its first use. But, if so, the above proposal is at risk of circularity: the origin of a file would be its first use, which would in turn be its openness, namely its creation or origin. ${ }^{18}$ Nor, finally, are origins conceivable as the initial token acquaintance relations grounding the files: as we have seen in the second part of $\S 4.3$, files can be acquaintanceless.

According to Fine (2007), the only admissible way to individuate files is by means of his own notion of coordination or representing as the same.

[I]t is hard to know what talk of mental files is meant to convey. Perhaps one thing it may reasonably be taken to convey is that certain items of information are stored together in a single "location", while other items of information are not. [...]

But we may now ask: in virtue of what will information be stored in the same location or in a different location? After all, there is nothing intrinsic to the idea of co-location which requires that co-located items should be related in any particular way. And surely the answer to the question is that the location will be the same when the information represents the object as the same. Thus mental files should be seen as a

${ }^{18}$ I have also criticized Sainsbury's, Tye's and Millikan's (2011: 102) proposal in 2019: $§ 5.3$ on the basis of my (2019: $§ 5.2)$ version of Pagin's (2013: 140) moth case, where two distinct files seem to intuitively share the same origin. Recanati has replied to me in his forthcoming article "Mental Files", defending Sainsbury's, Tye's and Millikan's proposal. However, his reply seems more successful if addressed against Pagin's original case than against my version of it. A case probably more persuasive than the moth cases (labelled the Superman case) is presented in my 2020. 
device for keeping track of when objects are coordinated (represented as-the-same) and $[\ldots]$ we should understand the workings of mental files in terms of coordination. (Fine 2007: 67-8; underlining mine) ${ }^{19}$

Fine's strategy for individuating mental files, which in his article "Comments on Scott Soames' 'Coordination Problems" (2010: 479-80) is more explicitly formulated and extended to non-descriptive modes of presentation in general, seems to me the best available in the philosophical literature: if there are really things like non-descriptive modes of presentation, it is reasonable to individuate them using equivalence classes of some suitable relation (coordination) that is not in turn reducible to modes of presentation.

Nonetheless, it is doubtable that even this strategy ultimately works. For, first, as we will see in $\S 5$, Fine's coordination is a semantic and thus interpersonal relation, whereas mental files are psychological and private modes of presentation. ${ }^{20}$ Second, coordination however conceived is not capable to individuate both fine-grained files and coarse-grained files of Recanati's theory, viz. static files and dynamic files respectively, the former being temporal stages of the latter. In order to illustrate this point, consider the following case from David Papineau (2006).

You see a bird at the bottom of your garden. You look at it closely, and at the same time think I haven't seen [that] in here before. Later on you can recall the bird in visual imagination, perhaps thinking I wonder if [that] was a migrant. (Papineau 2006: 113)

Recanati (2012: ch. 6 and 7) maintains that in Papineau's case, you deploy three distinct files about the bird: two fine-grained static files,

${ }^{19}$ Officially, Recanati disagrees with Fine's proposal, since he takes coordination (de jure coreference in his own terminology) to be accounted for by mental files (2012: 94, 95 and 2016: xi). It is interesting to note, however, that in some passages of his books 2012: viiin3 and 2016: 11, he talks of the items of information stored in the files as "coordinated".

${ }^{20}$ Fine's semantic coordination can rather be employed to individuate public files (beginning of $\$ 4.2$ ); conversely, a more suitable candidate for the relation that serves to individuate token mental files is, in principle, the cognitive coordination I will introduce in $§ 7.1$. As we will see, nevertheless, both these candidates are non-transitive relations; hence, both are inadequate for individuating mental files via alleged equivalence classes. 
one based on a token visual relation (demonstrative, viz. visual, file) and another based on a token memory relation (memory demonstrative or memory file), along with a third more coarse-grained dynamic file (recognitional demonstrative or recognitional file), based on the composition of the two aforementioned relations (re-acquaintance relation) and created by you by converting the aforementioned visual file into the aforementioned memory file, to the effect that these two finegrained files become consecutive temporal stages of the sole recognitional file. Now, the items of information (tokens) stored in the visual file and those stored in the memory file, as being in turn items of one and the same file, the recognitional file, are coordinated (in fact, you immediately recognize them as concerning the same bird); on the other hand, they also belong to distinct files, the visual file and the memory file. So, these two files are more fine-grained than (and thereby not individuated by) maximal classes of coordinated items of information. A third and crucial obstacle to the Finean proposal of individuating non-descriptive modes of presentation using equivalence classes of coordination is that, as Fine (2007: 106-7 and 2010: 480n2) himself admits, coordination is improbably a transitive relation.

Summing up, if modes of presentation are descriptive, they cannot solve Fine's "Bruce" case. On the other hand, if they are nondescriptive, at best they are secondary to coordination and at worst they lack identity conditions. This conclusion leads one to suspect that, contrary to what Frege thought and many contemporary philos-

ophers still think, coordination and not modes of presentation is the key notion to solve Frege's puzzle. But what exactly is coordination?

\section{Semantic relationism and Fine's solution to Frege's puzzle}

Coordination is the central notion of Fine's theory of meaning, semantic relationism.

Semantic coordination (first characterization): This is a two-place semantic relation holding primarily between two coreferring token names, $N_{1}$ and $N_{2}$, within a piece of discourse, $D$, and derivatively between the occurrences $o_{1}$ and $o_{2}$ of $N_{1}$ 's and $N_{2}$ 's referent that are included in the sequence of propositions expressed by $D$. The names $N_{1}$ and $N_{2}$, and thus the object occurrences $o_{1}$ and $o_{2}$, 
are positively coordinated (if and) only if no (sincere and reflective) hearer/reader who understands discourse $D$ can sensibly raise the question of whether $N_{1}$ and $N_{2}$ corefer. ${ }^{21}$ On the other hand, $N_{1}$ and $N_{2}$, and thus $o_{1}$ and $o_{2}$, are negatively coordinated if and only if they are not positively coordinated.

For instance, suppose that you say (2). A hearer who understands your statement but doubts that Hesperus is Phosphorus will sensibly raise the question of whether the names "Hesperus" and "Phosphorus" in (2) corefer. Hence, according to Fine's above characterization, these names are negatively coordinated. On the other hand, suppose that you say (1) intending to refer to the same heavenly body. Given your coreferential intention, for Fine no hearer who understands your statement (1) can sensibly question whether the two tokens of the name "Hesperus" corefer, to the effect that those tokens will be positively coordinated.

In Fine's semantics, coordination enters the semantic content of single statements and larger pieces of discourse. For example, statement (1) expresses the positively coordinated proposition (1p*), whose constituents are the singular proposition (1p) and the positive coordination link $C^{+}$holding between the token names "Hesperus" in (1), and derivatively between the two occurrences of the planet Venus in the proposition $\left(1 \mathrm{p}^{*}\right)$; by contrast, statement (2) expresses the negatively coordinated proposition $\left(2 \mathrm{p}^{*}\right)$, where $C^{-}$is the negative coordination link holding between the names "Hesperus" and "Phosphorus" in (2), and derivatively between the two occurrences of Venus in the proposition ( $\left.2 \mathrm{p}^{*}\right)$. Now, on Fine's view, (1) and (2) cognitively differ because they semantically differ, viz. they respectively express (1p*) and $\left(2 p^{*}\right)$.

$$
\begin{aligned}
& \left(1 \mathrm{p}^{*}\right)<<\text { Venus, }=\text {, Venus }>, C^{+}> \\
& \left(2 \mathrm{p}^{*}\right)<<\text { Venus, =, Venus }>, C^{->}
\end{aligned}
$$

Something similar happens in the "Bruce" case. Since statement (3*) is produced with the intention to refer to the same Bruce and statement $\left(3^{* *}\right)$ is produced with the intention to refer to two distinct alleged Bruces, the token names in $\left(3^{*}\right)$ are positively coordinated,

\footnotetext{
${ }^{21}$ The parenthetical phrases "if and" and "sincere and reflective" are my additions to Fine's (2007: 40) original characterization. Other readers of Fine 2007 have interpreted his characterization in the same way as me: see Salmon 2012: 430n31.
} 
whereas those in $\left(3^{* *}\right)$ are negatively coordinated. As a result, $\left(3^{*}\right)$ and $\left(3^{* *}\right)$ have different semantic contents: the former statement expresses a positively coordinated proposition whereas the latter expresses a negatively coordinated proposition. This semantic difference between $\left(3^{*}\right)$ and $\left(3^{* *}\right)$ accounts for their cognitive difference. So, Fine solves (any version of) Frege's puzzle by disallowing the move from step (b) to step (d) ( $\$ 1)$.

On the other hand, this move is composite, being formed by the moves from (b) to (c) and from (c) to (d). Which one of them does Fine disallow? He (2007: 37-9) claims that the move from (b) to (c) should be disallowed: although statements (1) and (2) express different propositions, $\left(1 \mathrm{p}^{*}\right)$ and $\left(2 \mathrm{p}^{*}\right)$, the names "Hesperus" and "Phosphorus" have the same semantic content, Venus. If so, semantic relationism violates the principle of Strong Compositionality, ${ }^{22}$ while it meets Millianism $(\S 2){ }^{23}$

Strong Compositionality: "[T]he semantic content of a [well-formed] compound expression is a composite entity composed in a particular manner of the semantic contents of the contentful component expressions." (Salmon 2012: 408)

On the other hand, after a closer inspection, one realizes that Fine actually disallows the move from (c) to (d). For when Fine affirms that "Hesperus" and "Phosphorus" have the same semantic content, he actually means that they have the same intrinsic content, which is just a component of their overall semantic content. In fact, the name "Hesperus" paired with another name also has extrinsic or relational content: e.g. the extrinsic content of the pair "Hesperus", "Hesperus" (accompanied by the speaker's intention to corefer) is a positive coordination link, while and the extrinsic content of the pair "Hespe-

\footnotetext{
${ }^{22}$ Strong Compositionality would be violated because the semantic content of compound expressions would be made up of the semantic contents of the composing terms plus coordination. Incidentally, it is worth noticing that coordination cannot be subsumed under the condition "composed in a particular manner" included in the formulation of Strong Compositionality: such a condition aims to capture the semantic difference between e.g. "Cicero admires Caesar" and "Caesar admires Cicero".

${ }^{23}$ This conclusion would justify Soames' (2014) claim that Fine's semantic relationism is a version of Millianism.
} 
rus", "Phosphorus" is a negative coordination link. In sum, for Fine, the overall semantic content of a proper name is not solely its referent; therefore, Millianism is given up within semantic relationism, as Fine (2007: 53) ultimately admits. By contrast, Strong Compositionality is met; what Fine rejects is rather Strong Compositionality*.

Strong Compositionality*: The (overall, i.e. intrinsic plus extrinsic) semantic content of a well-formed compound expression is a composite entity composed in a particular manner of the intrinsic contents of the contentful component expressions.

\section{Doubts about semantic coordination}

I agree with Fine that coordination is the right device to solve Frege's puzzle. But, unlike him, I think that coordination is more plausible if conceived as a non-semantic and subjective relation. This is what I am going to argue in the present section, viz. in $\S 6.2$ and $\S 6.3$, after having examined and then dismissed, in $\S 6.1$, various potential characterizations of the notion of semantic coordination (including the one formulated at the beginning of §5), thereby showing that such a notion is fundamentally obscure.

\subsection{The obscurity of semantic coordination}

Fine's characterization of coordination formulated at the beginning of $\S 5$ is flawed in several respects. First, it concerns not coordination simpliciter but coordination relative to a piece of discourse, whereas Fine (2010: 479 and personal communication) would like that coordination was a non-relativized relation. Second, such a characterization is subject to the following counterexample. Suppose that I say (6) and (7) (below), intending to refer to the same individual, the Polish musician and politician Ignacy Paderewski. Given my intention to corefer, the two token names of Paderewski in (6) and (7) are positively coordinated, according to Fine (personal communication). Now, assume that Peter hears my statements (6) and (7), and detects my coreferential intention; therefore, he understands such statements; nevertheless, he was strongly convinced and remains convinced, even after hearing me, that Paderewski the musician is not Paderewski the 
politician. As a result, he can still sensibly raise the question of whether the two tokens of "Paderewski" in (6) and (7) corefer, thus violating the characterization of coordination at the beginning of $\S 5 .{ }^{24}$

(6) Paderewski is a brilliant pianist.

(7) Paderewski is a charismatic statesman.

Third and most important, as I have maintained in my forthcoming article "Coordination, Understanding, and Semantic Requirements", the characterization in question is circular, for it involves the notion of understanding a piece of discourse containing two token names, which, on Fine's view, is grounded in coordination itself thereby generating a circle: for Fine, to understand a piece of discourse is a matter of grasping a coordinated sequence of propositions, i.e. a sequence that incorporates a coordination link/scheme as a constituent.

Fine (2007: 51) also offers a more technical characterization of coordination, involving the notion of strict coreference, in turn grounded in the notion of semantic requirement.

Semantic coordination (second characterization): Two coreferring token names $N_{1}$ and $N_{2}$ (and thus the object occurrences $o_{1}$ and $o_{2}$ "expressed" by $N_{1}$ and $N_{2}$ ) are positively (i.e. not negatively) coordinated if and only if they strictly corefer, i.e. if and only if it is a semantic requirement (or semantic necessity) that $N_{1}$ and $\mathrm{N}_{2}$ corefer.

In his forthcoming comments on my article "Coordinating, Understanding, and Semantic Requirements", Fine clarifies that this second characterization, which he renders non-circular by taking the notion of semantic requirement as primitive, is his only official definition of semantic coordination. To this, I (2019) have objected that Fine's notion of semantic requirement is too sophisticated to be taken as primitive: an analysis of it in terms of something simpler

\footnotetext{
${ }^{24}$ This counterexample can be bypassed if the condition that in the characterization at the beginning of $\S 5$ is indicated as necessary and sufficient for coordination is only taken to be sufficient for it. Note, however, that, as pointed out in $\mathrm{fn}$. 21, such a condition was originally intended by Fine (2007: 40) as necessary; so, the illustrated counterexample falsifies Fine's original characterization and thus the core of the characterization at the beginning of $\S 5$.
} 
would be desirable.

Based on ideas from Salmon (1993, 1993a: 93-5, 2012: 433n36), a clarificatory replacement for "semantic requirement" in Fine's technical characterization of coordination above could be "true solely by virtue of linguistic conventions", where "linguistic conventions" stand for both syntactic (in the logical sense) and semantic conventions. The characterization above would then be reformulated as follows.

Semantic coordination (third characterization): Two coreferring token names $N_{1}$ and $N_{2}$ are positively (i.e. not negatively) coordinated if and only if it is true solely by virtue of linguistic conventions that $N_{1}$ and $N_{2}$ corefer.

Which linguistic conventions exactly are responsible for the coordination between token names? Here is a prima facie appealing proposal.

Semantic coordination (fourth characterization): Two coreferring token names are positively (i.e. not negatively) coordinated if and only if they are tokens of the same name (type).

For instance, in statement (1) the token names "Hesperus" and "Hesperus" are positively coordinated because they are tokens of the same name, whereas in statement (2) the token names "Hesperus" and "Phosphorus" are negatively coordinated because they are tokens of different names. But what about Kripke's (1979) "Paderewski" case, where Peter mistakes the Polish statesman and pianist Ignacy Paderewski for two men, a musician and a politician both named "Paderewski"? This case seems to constitute a counterexample to the fourth characterization above: according to Fine (2007: ch. 4), the token names "Paderewski" in Peter's statements (6) and (7) are negatively coordinated; however, as Kaplan (1990: 110) confirms, only one name "Paderewski" referring to the statesman and pianist Ignacy Paderewski is contained in the public language. As a reasonable way out of this difficulty, it can be hypothesized that since Peter mistakes Paderewski for two men, his private language or idiolect contains two names "Paderewski" accidentally written and pronounced the same, 
say "Paderewski" ${ }_{1}$ and "Paderewski" ${ }_{2} \cdot{ }^{25}$ Thanks to this manoeuver, we are able to account, coherently with the fourth characterization, for Fine's claim that the token names "Paderewski" in Peter's statements (6) and (7) are negatively coordinated: they are negatively coordinated because they are tokens of different idiolect names, "Paderewski" and "Paderewski" ${ }_{2}$. Conversely, only one name "Paderewski", say "Paderewski", ${ }_{3}$, is contained in my idiolect (taking into account that I know that the musician Paderewski is the politician Paderewski), in accordance with Fine's claim that the token names "Paderewski" comprised in my statements (6) and (7) are positively coordinated. Something analogous can be said in the "Bruce" case: Susan's idiolect, unlike mine, contains two names "Bruce".

So, the names mentioned in the fourth characterization should be intended as belonging to idiolects rather than to public language. Yet some doubts about such a characterization arise even after this clarification. First, since idiolect names (unlike public-language names) are not sharable by speakers, it follows from the fourth characterization that no token name belonging to an idiolect will be positively coordinated with some token name belonging to a different idiolect. But this upshot clashes with our intuitions. For e.g. suppose that you learn your unique use of the name "Paderewski" from my unique use of it and suppose also that we both make no error on the identity of Paderewski. Intuitively, your tokens of "Paderewski" are positively coordinated with mine, despite their belonging to different idiolects. So, it seems that the fourth characterization is suitable to define intrapersonal coordination (i.e. coordination between token names of the same idiolect), but it fails to capture interpersonal coordination (i.e. coordination between token names of different idiolects). Kaplan (2011: 153-7) and Sam Cumming (2013: §3.1) have attempted to elucidate the notion of interpersonal coordination, labelled synching by Kaplan and alignment by Cumming. ${ }^{26}$ Unfortunately, Kaplan (2011: 154) has confessed to not knowing how to characterize it,

\footnotetext{
${ }^{25}$ The hypothesis that Peter's idiolect contains two names "Paderewski" is approved by Kaplan (personal communication).

${ }^{26}$ Cumming's alignment is actually a relation between mental symbols. Nonetheless, his "characterization" of alignment can be extended mutatis mutandis to natural-language idiolect names.
} 
while Cumming (2013: 385) has proposed a "characterization" of alignment which seems more a list of artificial constraints created ad hoc to achieve transitivity than a genuine and intuitive characterization. ${ }^{27}$ Another problem for the fourth characterization concerns its involving a category of expressions, proper names and in particular idiolect names, whose identity is a controversial matter. Most importantly, on Fine's (2007: 71-2) view, coordination must not be grounded in modes of presentation however conceived (see the second part of §4.4), whereas proper names are for some philosophers a candidate for modes of presentation..$^{28}$ Finally, it should be observed that according to Salmon (personal communication), there is just one name "Paderewski" of the Polish musician and politician Ignacy Paderewski not only in the public language but also in Peter's (and anyone else's) idiolect; if this is correct, the adoption of the fourth characterization is useless for a semantic relationist to solve Frege's puzzle.

In my opinion, the philosophical literature does not offer anything better for characterizing semantic coordination than the (defective) proposals examined so far. In fact, consider the following alternative characterization, which takes its cue from Angel Pinillos 2011 and Thea Goodsell 2014.

Semantic coordination (fifth characterization): Two coreferring token names $N_{1}$ and $N_{2}$ within a piece of discourse $D$ are positively (i.e. not negatively) coordinated if and only if any hearer/reader who understands discourse $D$ immediately knows a priori that $N_{1}$ and $N_{2}$ corefer.

Clearly, this proposal suffers from the same difficulties as Fine's first characterization (beginning of §5). In addition, the following question arises: what counts as immediate knowledge a priori?

In [a fairly] intuitive sense, "immediate knowledge" is instantly acquired on [understanding discourse $D$ ], and is not the product of conscious reasoning, though it may be grounded in other knowledge, for example knowledge of the general rules of the language. (Goodsell 2014: 309; underlining mine)

${ }^{27}$ More on Kaplan's and Cumming's conceptions of interpersonal coordination is in my 2018.

${ }^{28}$ See Kaplan 1989a: 598. 
This passage suggests that the sophisticated notion of immediate knowledge a priori could be conveniently replaced with a more intuitive notion such as linguistic convention; but this replacement would end up down the same blind alley as the third and then the fourth characterization (first part of this sub-section). Finally, according to Salmon (1993a), (1) and (2) are both a priori true; if so, appealing to the notion of apriority would arguably be unhelpful to solve Frege's puzzle.

Alternatively, John Campbell (1987) has proposed to characterize semantic coordination (presumption of identity in his own terminology) in terms of a notion that Fine $(2007,2014)$ calls manifest validity.

Let us say that an inference is manifestly valid if a rational subject would be justified in drawing the inference no matter what her access to the premisses. (Fine 2014: 425)

Roughly, Campbell's characterization of coordination is as follows.

Semantic coordination (sixth characterization): Two coreferring token names $N_{1}$ and $N_{2}$ contained in the statements $\left\ulcorner N_{1}\right.$ is $\left.\varphi\right\urcorner$ and $\left\ulcorner N_{2}\right.$ is $\psi\urcorner$ are positively (i.e. not negatively) coordinated if and only if the inference from these two statements to $\ulcorner$ Someone/thing is $\varphi$ and $\psi\urcorner$ is manifestly valid (viz. a rational subject would be justified in drawing such an inference no matter what her access to the premise $\left\ulcorner N_{1}\right.$ is $\left.\left.N_{2}\right\urcorner\right)^{29}$

In my opinion, Campbell's proposal is highly questionable: usually, we define complex philosophical notions in terms of simpler notions; but the notion of manifest validity is by far more sophisticated than that of coordination. In fact, Fine (2007: 82-3) wisely uses coordination to account for manifest validity, rather than the other way around.

Finally, Recanati $(2016: 18,26)$ upholds a twofold characterization of coordination (weak and strong de jure coreference in his own terminology): something like the characterisation below, which merges Fine's first characterization at the beginning of $\$ 5$ and Campbell's above characterization (presumption of identity/coreference). As such, it inherits the problems of both.

${ }^{29}$ To borrow analysis and terminology from Recanati 2012: 47-9, 88, we might say that the subject in question immediately, viz. non-conceptually, recognizes the referent of $N_{1}$ and $N_{2}$ as the same, namely he does so without an explicit or implicit identity judgment. 
Semantic coordination (seventh characterization): Two coreferring token names $N_{1}$ and $N_{2}$ within a piece of discourse $D$ produced by a speaker/writer $s$ are positively (i.e. not negatively) coordinated (if and) only if $s$ presumes coreference between $N_{1}$ and $N_{2}$ and, as a result, any hearer/reader who understands discourse $D$ knows that $N_{1}$ and $N_{2}$ corefer. $^{30}$

\subsection{Coordination as a subjective relation}

Let us set aside the problem of how to define semantic coordination, taking for granted the first characterization at the beginning of $\S 5$, which is, after all, the most intuitive among the examined characterizations. In this sub-section, pace Fine (2007), I would like to argue with an example that it is more plausible to conceive coordination as a subjective relation rather than as a semantic and thereby intersubjective relation. Suppose that an ordinary speaker, Lidia, says (2), having absolutely no doubt that her statement (2) is true, i.e. that the names "Hesperus" and "Phosphorus" corefer. On the other hand, since current or potential hearers of Lidia who understand her statement could sensibly question whether "Hesperus" and "Phosphorus" corefer, these names are negatively coordinated, based on Fine's first characterization. Therefore, the proposition Lidia conveys by uttering (2) is also negatively coordinated. But why should such a proposition be coordinated in that way? After all, Lidia has absolutely no doubt that "Hesperus" and "Phosphorus" corefer. Also, she could be totally unaware of doubts that current or potential hearers of hers may have about the fact that these names corefer; thus, as a result of adopting Fine's intersubjective conception of coordination, it turns out that Lidia conveys something not transparent to her.

Alternatively and more plausibly, we could maintain that whereas

${ }^{30}$ The parenthetical phrase "if and" is my addition to Recanati's (2016: 18) original characterization. In his original characterization, Recanati considers the possibility that $N_{1}$ or $N_{2}$ do not refer. I set aside this possibility in all examined characterizations: like Fine (2007: 126), Graham Priest (2016) and others, I tend to think that all given proper names refer to something (concrete or abstract, existent or nonexistent). Incidentally, concerning the distinction between given proper names (e.g. the name "David", given to Kaplan and no one else) and generic proper names (e.g. the name "David" shared by all Davids, which indeed fails to refer), see Kaplan 1990. 
Lidia's doubtful hearers indeed negatively coordinate "Hesperus" and "Phosphorus" in (2), she positively coordinates them. In general, it seems reasonable to maintain that the way two token names are coordinated may vary from one subject to another, thus making coordination a subjective and consequently a non-semantic relation.

\subsection{Coordination as a non-semantic relation}

As a further argument for the anti-Finean thesis that coordination is a non-semantic relation, consider the following case.

When [Carl Hempel, the distinguished philosopher of science,] moved to Princeton, some of the philosophers there found the name "Carl" too Germanic for their taste and decided to use the English name "Peter" in its place. It is not that they re-christened Hempel with the name "Peter"; rather, they decided to use the name "Peter" as a variant of the name "Carl". [...] Someone who [...] failed to recognize that the two names were coreferential would thereby display his lack of understanding of the [...] language [they belong to]. (Fine 2007: 46-7)

Hence, based on Fine's first characterization, the name "Carl Hempel" and its variant "Peter Hempel" are positively coordinated. Now, consider a speaker, Sam, who does not detect the positive coordination link between "Carl Hempel" and "Peter Hempel", and is therefore unsure whether Carl Hempel is Peter Hempel. He then asks:

(8) Is Carl Hempel the same man as Peter Hempel?

It seems clear that Sam should not be blamed for not understanding what he is asking as a consequence of not detecting the positive (according to Fine) coordination link between his tokens of "Carl Hempel" and "Peter Hempel": the requirement that Sam must detect such a link in order to sensibly ask (8) is obviously too strong. Now, the fact that it is possible to (semantically) understand a token sentence without detecting a coordination link between its components falsifies the thesis that coordination is a semantic relation. ${ }^{31}$

${ }^{31}$ This objection takes its cue from Soames 2015: 127. In Soames' original version of the objection, Peter asks:

$\left(8^{*}\right)$ Is Paderewski the musician the same man as Paderewski the statesman? 


\section{Cognitive relationism and my solution to Frege's puzzle}

In my opinion, the most straightforward way for a relationalist to bypass the objections raised in $\S 6.2$ and $\S 6.3$ is to conceive coordination as a non-semantic and subjective relation. In doing so, coordination is retained, while semantic relationalism is dismissed as the correct theory of meaning. On the other hand, Fregeanism (i.e. the theory, originating with Frege, according to which the semantic contents of linguistic expressions are senses, namely modes of presentation of the denotations of the expressions) must also be given up: as we have seen, if senses are descriptive modes of presentation, they are unable to solve the "Bruce" version of Frege's puzzle $(\S 3)$; and if they are non-descriptive, their identity conditions are indeterminate (§4.4). It is therefore quite natural to adopt Millian Russellianism (§2) as the correct theory of meaning: according to Millian Russellianism, the basic building blocks of semantic content are not modes of presentation but just individuals, attributes and functions.

Frege's puzzle will then be solved by disallowing the move from step (a) to step (b) (\$1). For, as we have seen in $\S 2$, within the MillianRussellian semantics, statements (1) and (2) have the same semantic content, i.e. the singular proposition (1p), whereas they cognitively differ (on the basis of Cognitive Difference, §1): e.g. Hammurabi believes that (1) is true and (2) is false, consequently believing and disbelieving the proposition (1p). In order to explain how Hammurabi can do so rationally, we no longer appeal to non-semantic modes of presentation (for modes of presentation of any sort have been rejected). Instead, we employ non-semantic and subjective coordination

Soames points out that Peter cannot be blamed for not understanding his own question as a consequence of his doubting the identity of Paderewski.

Soames' version of the objection does not succeed though: it assumes that within semantic relationism the two tokens of "Paderewski" in $\left(8^{*}\right)$ are positively coordinated, whereas in fact for Fine (personal communication) they are negatively coordinated, being produced by someone (Peter) who is unsure whether Paderewski the musician is Paderewski the statesman. Conversely, in my version of the objection, the positivity of the coordination link between "Carl Hempel" and "Peter Hempel" is imposed by the fact that one name is a variant of the other, taking for granted the quotation from Fine himself reported at the beginning of $\S 6.3$ and his first characterization of semantic coordination. 
as follows: Hammurabi simultaneously believes the proposition (1p) and its negation, $(\sim 1 p)$, by negatively coordinating one occurrence of Venus in ( $\sim 1 \mathrm{p})$, say the first, with both its occurrences in (1p), and he also negatively coordinates its two occurrences in $(\sim 1 \mathrm{p})$ whereas the two occurrences in (1p) are positively coordinated for him.

$$
(\sim 1 \mathrm{p})<\text { Venus, } \neq \text {, Venus }>
$$

The aforementioned negative coordination links within Hammurabi's believed propositions assure his rationality, taking for granted the following quite plausible constraint on coordination and rationality.

New Rationality Constraint: A rational subject $s$ cannot believe the Russellian proposition $<<a, F>$, CONJ, $<<a, F>$, NEG $>>$, where CONJ is the function of conjunction and NEG is the function of negation, by positively coordinating the two occurrences of the individual $a$ and by positively coordinating the two occurrences of the property $F$. Neither can $s$, as a rational subject, believe the Russellian proposition $<a, \neq, a>$ by positively coordinating the two occurrences of $a$.

This solution to Frege's puzzle, which combines the Millian-Russellian semantics with a notion of non-semantic and subjective coordination, can easily be extended from the "Hesperus"/"Phosphorus" case to the "Bruce" case: although (in accordance with the MillianRussellian semantics) $\left(3^{*}\right)$ and $\left(3^{* *}\right)$ in $\S 3$ have the same semantic content, namely the singular proposition (3p) below, these two statements cognitively differ, given that a rational subject, Susan, believes the propositions (3p) and ( $\sim 3 p)$ by negatively coordinating say the first occurrence of Bruce in ( $\sim 3 p)$ with both his occurrences in (3p), and she also negatively coordinates his two occurrences in $(\sim 3 p)$ whereas the two occurrences in (3p) are positively coordinated for her.

$$
\begin{aligned}
& (3 p)<\text { Bruce, }=, \text { Bruce }> \\
& (\sim 3 p)<\text { Bruce, } \neq, \text { Bruce }>
\end{aligned}
$$

Using non-semantic and subjective coordination, we can even throw light on the notion of subjective cognitive content. Whereas within a Millian-Russellian framework public cognitive content is arguably 
identical to semantic content (i.e. Russellian propositions), ${ }^{32}$ subjective cognitive content can be conceived, at least in the case of identity statements, as cognitively coordinated propositions: e.g. the subjective (cognitive) content associated by Hammurabi to statement (1) is the positively coordinated proposition $\left(1 \mathrm{p}_{\mathrm{H}}^{*}\right)$, whereas the subjective content associated by Hammurabi to statement (2) is the negatively coordinated proposition $\left(2 \mathrm{p}_{\mathrm{H}}^{*}\right)$; conversely, the subjective content associated by Lidia (who, unlike Hammurabi, knows that "Hesperus" and "Phosphorus" corefer) with both statements (1) and (2) is the positively coordinated proposition $\left(1 \mathrm{p}_{\mathrm{L}}^{*}\right) \cdot{ }^{33}$

$$
\begin{aligned}
& \left(1 \mathrm{p}^{*}{ }_{\mathrm{H}}\right)<<\text { Venus, =, Venus }>, C_{H^{+}}> \\
& \left(2 \mathrm{p}^{*}{ }_{\mathrm{H}}\right)<<\text { Venus, =, Venus }>, C_{H^{-}}> \\
& \left(1 \mathrm{p}^{*}{ }_{\mathrm{L}}\right)<<\text { Venus, =, Venus }>, C_{L^{+}}>
\end{aligned}
$$

\subsection{Cognitive coordination}

I wish to propose the following characterization for the notion of non-semantic and subjective coordination involved in the solution to Frege's puzzle and in the characterization of subjective content outlined above.

Cognitive coordination: This is a three-place non-semantic relation holding between a rational subject, $s$, and a pair of occurrences, $o_{1}$ and $o_{2}$, of the same or different objects, included in the same or different Russellian propositions entertained by $s$; derivatively but equivalently, coordination also holds between $s$ and a pair of token terms, $T_{1}$ and $T_{2}$, having $o_{1}$ and $o_{2}$ as semantic contents and

${ }^{32}$ See Salmon 1986: ch. 1 and 2, and Soames 2015.

${ }^{33}$ In order to exhaustively account for the notion of subjective content in cases different from that of identity statements (e.g. a case where Susan utters twice and separately, i.e. within two distinct discourses, the sentence "Bruce is wearing pink pajamas" with the intention to refer to the two alleged Bruces), we need to introduce special occurrences of Russellian propositions (viz. two occurrences of the Russellian proposition $<$ Bruce, wearing pink pajamas $>$ ). Concerning the nature and the identity of such occurrences, see my 2019: $\S 8$ and $\S 9$. 
being included in the same or different statements, made competently by $s$, which express(es) the aforementioned proposition(s). Occurrences $o_{1}$ and $o_{2}$, and thus terms $T_{1}$ and $T_{2}$, are positively (i.e. not negatively) coordinated for $s$ if and only if $s$ treats $o_{1}$ and $o_{2}$ as occurrences of the same object, i.e. if and only if the following two conditions are jointly satisfied:

(j) $s$ (correctly or incorrectly) takes $o_{1}$ and $o_{2}$ as occurrences of the same object;

(jj) it is not the case that $s$ does as if $\mathrm{s} /$ he her/himself (i.e. $s$ ) did not take $o_{1}$ and $o_{2}$ as occurrences of the same object.

The relation of cognitive coordination or treating as is evidently grounded in two more fundamental relations: taking as, involved in condition (j); and doing as if, involved in condition (jj). Since some neurobiologists, in particular Rodrigo Quian Quiroga (2005 with al., 2012), are investigating the notion of taking as (or rather recognizing, i.e. correct taking as), I suggest taking taking as to be philosophically primitive, letting neurobiologists the task of elucidating it. ${ }^{34}$ Doing as if is a sort of simulation of taking as; so, the former relation can be regarded as grounded in the latter. Indeed, a partial reduction of doing as if to taking as can be attempted along the following lines.

Partial Reduction of doing as if to taking as: Let $\left\langle_{a}, F\right\rangle_{1}$ and $\left\langle_{a}, F\right\rangle_{2}$ be two occurrences of the Russellian proposition $\left.<_{a}, F\right\rangle$ entertained by a rational subject $s$. If $s$ takes the two occurrences of $a$ within $\left.<_{a}, F\right\rangle_{1}$ and $\left.<_{a}, F\right\rangle_{2}$ as occurrences of the same individual, takes the two occurrences of $F$ as occurrences of the same property, but does not take the two occurrences of $\langle a, F\rangle$ in question as occurrences of the same Russellian proposition, then either $s$ does as if the two occurrences of $a$ are not occurrences of the same individual, or $s$ does as if the two occurrences of $F$ are

\footnotetext{
${ }^{34}$ I therefore disagree with Salmon's (2012: 437n40) philosophical characterization of taking as in terms of guises and with Recanati's (2012: 94-5) philosophical explanation of taking as (internal coreference in his own terminology) in terms of (linked) files. Note also that the notion of taking as is simpler than that of mode of presentation (guise, mental file, etc.); this is another reason not to analyse the former notion in terms of the latter.
} 
not occurrences of the same property.

The "Hesperus"/"Phosphorus" case (as well as the other previously examined cases) offers paradigmatic illustration of taking as and thus of cognitive coordination. Hammurabi takes the two token names "Hesperus" in (1) as coreferring and, correspondingly, takes the two occurrences of Venus in $\left(1 \mathrm{p}_{\mathrm{H}}^{*}\right)$ as occurrences of the same heavenly body. Since Hammurabi has no reason to do as if such names were not coreferential and to do as if the corresponding occurrences were not occurrences of the same heavenly body, we conclude that those names and occurrences are positively coordinated for him, given that both conditions (j) and (jj) are met. Conversely, Hammurabi takes "Hesperus" and "Phosphorus" in (2) as non-coreferring and, correspondingly, takes the two occurrences of Venus in $\left(2 \mathrm{p}_{\mathrm{H}}^{*}\right)$ as occurrences of different heavenly bodies; the fact that condition $(j)$ is not fulfilled suffices to conclude that "Hesperus" and "Phosphorus" in (2) and the corresponding occurrences of Venus in $\left(2 \mathrm{p}_{\mathrm{H}}{ }_{\mathrm{H}}\right)$ are negatively coordinated for Hammurabi. ${ }^{35}$

Here is, now, an example of cognitive coordination emphasizing the role of doing as if, call it the "Hesperus"/"Phosphorus" belief-reporting case. Suppose that Lidia says (9) (below). Since she knows that "Hesperus" and "Phosphorus" corefer, she takes these names as coreferring; so condition ( $\mathrm{j}$ ) of cognitive coordination is met. On the other hand, Lidia does as if "Hesperus" and "Phosphorus" were not coreferential in (9). She has a good reason to do so: she is reporting Hammurabi's (non-)belief(s) and she knows that Hammurabi does not know that these name corefer. In a way, Lidia simulates Hummurabi's taking "Hesperus" and "Phosphorus" as non-coreferential by doing as if they were so. ${ }^{36}$ From the fact that condition (jj) is

\footnotetext{
${ }^{35}$ For analogous reasons, "Carl Hempel” and "Peter Hempel” in (8) are negatively coordinated for Sam $(\S 6.3)$.

${ }^{36}$ Coherently with this, in my 2018 I maintain that to fully (i.e. both semantically and cognitively) understand a statement is a matter of grasping its Russellian content plus detecting the speaker's coordination links between the components of such content, while correctly reporting a belief from a both semantic and cognitive viewpoint is a matter of reporting its Russellian content plus simulating (by exploiting the relation of doing as if) the believer's coordination links between the components of such content. So, neither cognitive understanding nor correctly
} 
not satisfied, we conclude that "Hesperus" and "Phosphorus" in (9) are negatively coordinated for her. Note that the negative coordination link between these names in (9) and between the corresponding occurrences of Venus in the self-contradictory Russellian proposition (9p) expressed by (9) accounts for Lidia's rationally asserting (9) and believing (9p), in accordance with the New Rationality Constraint (first part of $\S 7$ ).

(9) Hammurabi believes that Hesperus is visible is in the evening, but Hammurabi does not believe that Phosphorus is visible in the evening.

(9p) $<<$ Hammurabi, believing, $<$ Venus, being visible in the evening $>>$, CONJ, $<<$ Hammurabi, believing, < Venus, being visible in the evening $>>, N E G>>$

The "Hesperus"/"Phosphorus" belief-reporting case is also useful to illustrate the Partial Reduction of doing as if to taking as formulated in the first part of this sub-section. As we have seen, Lidia does as if "Hesperus" and "Phosphorus" in (9) were not coreferential and correspondingly does as if the two occurrences of Venus in (9p) were not occurrences of the same heavenly body (despite knowing that they are so). In fact, she rationally takes the two occurrences of the proposition $<$ Venus, being visible in the evening $>$ within the selfcontradictory proposition (9p) as occurrences of different propositions, in accordance with Partial Reduction.

Finally, it is important to note that cognitive coordination is not a transitive relation. E.g., as we have seen in $§ 6.2$, in Lidia's (unlike Hammurabi's) statement (2) "Hesperus" and "Phosphorus" are positively coordinated for her; and, as we have just ascertained above, "Hesperus" and "Phosphorus" in Lidia's report (9) are negatively (i.e. not positively) coordinated for her. On the other hand, the two tokens of "Hesperus" as well as the two tokens of "Phosphorus" in (2) and (9) are positively coordinated for her. It follows that (positive)

belief reporting from a cognitive viewpoint does involve interpersonal coordination (which, as pointed out in $\S 6.1$, is very difficult to characterize) or involve the sharing of a pragmatically conveyed content (besides the semantically expressed Russellian proposition) pace Salmon (1986: ch. 8) and in accordance with what Braun and Saul (2002) and Saul (2007) have persuasively argued. 
cognitive coordination is not transitive. Therefore, it cannot be employed to individuate non-descriptive modes of presentation via alleged equivalence classes, following the Finean strategy hypothesized at the end of $\S 4.4 .^{37}$

\section{Conclusion}

In this paper I have defended the Millian-Russellian semantics and its standard strategy for resolving Frege's puzzle, which consists in disallowing the move from step (a) to step (b) in $\S 1$. On the other hand, unlike Millian-Russellian theorists such as Salmon and Braun, I have accounted for the cognitive difference between (1) and (2), and between $\left(3^{*}\right)$ and $\left(3^{* *}\right)$ as well, by appealing to cognitive coordination instead of the highly disputable notion of (non-semantic) mode of presentation. My notion of coordination differs from Fine's and has at least two advantages in comparison with the latter: it is clearly characterized; and it is able to account for cases where coordination intuitively appears as a subjective and non-semantic relation. ${ }^{38}$

Paolo Bonardi

Department of History and Philosophy of Science

University of Tokyo 3-8-1, Komaba, Meguro-ku

Tokyo 153-8902

Japan

pbonardi1@gmail.com

\footnotetext{
${ }^{37}$ Further counterexamples to the transitivity of cognitive coordination are presented in my 2018 and 2019.

${ }^{38}$ Previous drafts of this manuscript were presented in 2014 in the PhilEAs Conference at the Université de Genève, in the Mind \& Language Seminar at the Institut Jean Nicod (Paris), and in 2015 at the Central Division Meeting of the American Philosophical Association in Saint Louis, in the Graduate Seminar of the Philosophy Department at the University of California Santa Barbara and in Thinking the Same: A Workshop on Mental Files at Boğaziçi University (Istanbul); I am grateful to the audiences of those presentations for their helpful comments. A special thanks to Kit Fine, David Kaplan, Zachary Miller, Nathan Salmon, Scott Soames and Chulmin Yoon for discussions on specific points of my paper and to François Recanati for comments on a previous draft of $\S 4$.
} 


\section{References}

Bonardi, Paolo. 2018. A farewell to the creatures of darkness. Manuscript.

Bonardi, Paolo. 2019. Manifest validity and beyond: an inquiry into the nature of coordination and the identity of guises and propositional-attitude states. Linguistics and Philosophy 42(5): 475-515.

Bonardi, Paolo. 2020. Rational belief and dialetheism. Manuscript.

Bonardi, Paolo. Forthcoming. Coordination, understanding, and semantic requirements. In Metaphysics, Meaning, and Modality: Themes from Kit Fine, ed. by M. Dumitru. Oxford: Oxford University Press.

Braun, David. 1998. Understanding belief reports. Philosophical Review 107(4): 555-95.

Braun, David. 2002. Cognitive significance, attitude ascriptions, and ways of believing propositions. Philosophical Studies 108(1): 65-81.

Braun, David. 2006. Illogical, but rational. Noûs 40(2): 376-9.

Braun, David and Saul, Jennifer. 2002. Simple sentences, substitutions, and mistaken evaluations. Philosophical Studies 111(1): 1-41.

Campbell, John. 1987. Is sense transparent? Proceedings of the Aristotelian Society 88: 273-92.

Cumming, Sam. 2013. Creatures of darkness. Analytic Philosophy 54(4): 379-400.

Fine, Kit. 2007. Semantic Relationism. Oxford: Blackwell.

Fine, Kit. 2010. Comments on Scott Soames' "Coordination Problems". Philosophy and Phenomenological Research 81(2): 475-84.

Fine, Kit. 2014. Recurrence: a rejoinder. Philosophical Studies 169(3): 425-8.

Fine, Kit. Forthcoming. Comments on Paolo Bonardi's "Coordination, understanding, and semantic requirements". In Metaphysics, Meaning, and Modality: Themes from Kit Fine, ed. by M. Dumitru. Oxford: Oxford University Press.

Frege, Gottlob. 1892. Über Sinn und Bedeutung. Zeitschrift für Philosophie und philosophische Kritik. Translated as "On Sense and Reference" in Translations from the Philosophical Writings of Gottlob Frege, ed. by P. Geach and M. Black. London: Blackwell, 1952.

Goodsell, Thea. 2014. Is de jure coreference non-transitive? Philosophical Studies 167(2): 291-312.

Hall, Keith. 2013. Acquaintance and mental files. Disputatio 5(36): 119-32.

Kaplan, David. 1968. Quantifying in. Synthese 19(1/2): 178-214.

Kaplan, David. 1989. Demonstratives. In Themes from Kaplan, ed. by J. Almog, J. Perry and H. Wettstein, 481-563. Oxford: Oxford University Press.

Kaplan, David. 1989a. Afterthoughts. In Themes from Kaplan, ed. by J. Almog, J. Perry and H. Wettstein, 565-614. Oxford: Oxford University Press.

Kaplan, David. 1990. Words. Aristotelian Society Supplementary Volume 64(1): 93-119.

Kaplan, David. 2011. An idea of Donnellan. In Having in Mind: The Philosophy of Keith Donnellan, ed. by J. Almog and P. Leonardi, 122-75. Oxford: Oxford 
University Press.

Kripke, Saul A. 1979. A puzzle about belief. In Meaning and Use, ed. by A. Margalit, 239-83. Dordrecht: Reidel.

Kripke, Saul A. 1980. Naming and Necessity. Cambridge, Mass.: Harvard University Press.

Murez, Michael. 2011. Mental files and the dynamics of identity. Manuscript.

Pagin, Peter. 2013. The cognitive significance of mental files. Disputatio 5(36): $133-45$.

Papineau, David. 2006. Phenomenal and perceptual concepts. In Phenomenal Concepts and Phenomenal Knowledge: New Essays on Consciousness and Physicalism, ed. by T. Alter and S. Walter, 111-44. New York: Oxford University Press.

Pinillos, Angel. 2011. Coreference and meaning. Philosophical Studies 154(2): 301-24.

Priest, Graham. 2016. Towards Non-Being. Second edition. New York: Oxford University Press.

Pryor, Jim. 2016. Mental graphs. Review of Philosophy and Psychology 7(2): 309-41.

Quiroga, Rodrigo Quian. 2012. Concept cells: the building blocks of declarative memory functions. Nature Reviews Neuroscience 13(8): 587-97.

Quiroga, Rodrigo Quian, Leila Reddy, Gabriel Kreiman, Christof Koch and Itzhak Fried. 2005. Invariant visual representation by single neurons in the human brain. Nature 435(7045): 1102-7.

Recanati, François. 2012. Mental Files. Oxford: Oxford University Press.

Recanati, François. 2013. Mental files: replies to my critics. Disputatio 5(36): 207-42.

Recanati, François. 2016. Mental Files in Flux. Oxford: Oxford University Press.

Recanati, François. Forthcoming. Mental files. In The Cambridge Handbook of the Philosophy of Language, ed. by P. Stalmaszczyk. Cambridge: Cambridge University Press.

Sainsbury, Mark and Michael Tye. 2012. Seven Puzzles of Thought and How to Solve Them: An Originalist Theory of Concepts. Oxford: Oxford University Press.

Sainsbury, Mark; Michael Tye and Ruth G. Millikan. 2011. Concepts. Proceedings of the Aristotelian Society, Supplementary Volumes 85: 101-24.

Salmon, Nathan. 1986. Frege's Puzzle. Cambridge, Mass.: MIT Press.

Salmon, Nathan. 1989. Illogical belief. Philosophical Perspectives 3: 243-85.

Salmon, Nathan. 1993. Analiticity and apriority. Philosophical Perspectives 7: 125-33.

Salmon, Nathan. 1993a. Relative and absolute apriority. Philosophical Studies 69(1): 83-100.

Salmon, Nathan. 1998. Nonexistence. Philosophical Perspectives 1: 49-108.

Salmon, Nathan. 2006. The Resilience of illogical belief. Noûs 40(2): 369-75.

Salmon, Nathan. 2012. Recurrence. Philosophical Studies 159(3): 407-41.

Saul, Jennifer. 2007. Simple Sentences, Substitution, and Intuitions. New York: Oxford University Press.

Schiffer, Stephen. 1990. The mode-of-presentation problem. In Propositional Attitudes: The Role of Content in Logic, Language, and Mind, ed. by C.A. 
Anderson and J. Owens, 249-68. Stanford: CSLI Publications.

Soames, Scott. 1987. Direct reference, propositional attitudes, and semantic content. Philosophical Topics 15(1): 47-87.

Soames, Scott. 2002. Beyond Rigidity: The Unfinished Agenda of Naming and Necessity. Oxford: Oxford University Press.

Soames, Scott. 2014. Two versions of Millianism. In Analytic Philosophy in America: and Other Historical and Contemporary Essays. Princeton: Princeton University Press.

Soames, Scott. 2015. Rethinking Language, Mind, and Meaning. Princeton: Princeton University Press. 